\title{
Simultaneous and enantioselective liquid chromatographic determination of eslicarbazepine acetate, $S$-licarbazepine, $R$-licarbazepine and oxcarbazepine in mouse tissue samples using ultraviolet detection
}

\author{
Gilberto Alves ${ }^{a}$, Isabel Figueiredo ${ }^{a}$, Margarida Castel-Branco ${ }^{\mathrm{a}}$, \\ Ana Loureiro $^{\mathrm{b}}$, Amílcar Falcão ${ }^{\mathrm{a}, *}$, Margarida Caramona ${ }^{\mathrm{a}}$ \\ ${ }^{a}$ Laboratory of Pharmacology, Faculty of Pharmacy, Coimbra University, 3000-141 Coimbra, Portugal \\ ${ }^{\mathrm{b}}$ Department of Research and Development, BIAL, 4745-457 S. Mamede do Coronado, Portugal
}

Received 5 March 2007; received in revised form 30 May 2007; accepted 31 May 2007

Available online 3 June 2007

\begin{abstract}
Herein is reported, for the first time, a simple and reliable chiral reversed-phase liquid chromatographic method coupled to ultraviolet (UV) detection for simultaneous determination of eslicarbazepine acetate (ESL) and its metabolites, $S$-licarbazepine $(S$-LC), $R$-licarbazepine $(R$-LC) and oxcarbazepine (OXC), in mouse plasma and brain, liver and kidney tissue homogenates. All analytes and the internal standard were extracted from plasma and tissue homogenates by a solid-phase extraction procedure using Waters Oasis ${ }^{\circledR}$ hydrophilic-lipophilic balance cartridges. The chromatographic separation was performed by isocratic elution with water/methanol $(88: 12, \mathrm{v} / \mathrm{v})$, pumped at a flow rate of $0.7 \mathrm{~mL} \mathrm{~min}{ }^{-1}$, on a LichroCART 250-4 ChiraDex ( $\beta$-cyclodextrin, $5 \mu \mathrm{m})$ column at $30^{\circ} \mathrm{C}$. The UV detector was set at $225 \mathrm{~nm}$. Calibration curves were linear $\left(r^{2} \geq 0.996\right)$ in the ranges $0.4-8 \mu \mathrm{g} \mathrm{mL}^{-1}, 0.1-1.5 \mu \mathrm{g} \mathrm{mL}^{-1}$ and $0.1-2 \mu \mathrm{g} \mathrm{mL}^{-1}$ for ESL and OXC and in the ranges $0.4-80 \mu \mathrm{g} \mathrm{mL}^{-1}, 0.1-15 \mu \mathrm{g} \mathrm{mL}-1$ and $0.1-20 \mu \mathrm{g} \mathrm{mL}^{-1}$ for $R$-LC and $S$-LC in plasma, brain and liver/kidney homogenates, respectively. The overall precision not exceeded $11.6 \%$ $(\% \mathrm{CV})$ and the accuracy ranged from -3.79 to $3.84 \%$ (\% bias), considering all analytes in all matrices. Hence, this method will be a useful tool to characterize the pharmacokinetic disposition of ESL in mice.
\end{abstract}

(C) 2007 Elsevier B.V. All rights reserved.

Keywords: Eslicarbazepine acetate; Oxcarbazepine; Mouse tissue samples; Enantioselective liquid chromatography; Bioanalytical method validation

\section{Introduction}

Eslicarbazepine acetate (ESL) [S-(-)-10-acetoxy-10,11dihydro-5H-dibenz/b,f/azepine-5-carboxamide], previously known as BIA 2-093, is a novel central nervous system (CNS)-active drug presently completing phase III clinical trials, as add-on therapy in refractory partial epilepsy, and undergoing phase II clinical trials, as monotherapy in partial epilepsy and in bipolar disorder [1]. Chemically, it shares with oxcarbazepine (OXC) the dibenzazepine nucleus bearing the 5 -carboxamide substituent, but is structurally different at the

\footnotetext{
* Corresponding author. Tel.: +351 239 855089; fax: +351 239855099

E-mail address: acfalcao@ff.uc.pt (A. Falcão).
}

10,11-position (Fig. 1) [2]. These molecular variations result in differences in their metabolism and, consequently, in their pharmacological properties. Briefly, OXC is an achiral prodrug which, in humans, is stereoselectivelly reduced in liver to the pharmacologically active licarbazepine metabolite, appearing in plasma as $S$-licarbazepine ( $S$-LC) and $R$-licarbazepine $(R$-LC) in approximately a 4:1 enantiomeric ratio [3,4]. On the other hand, the chiral prodrug ESL is quickly and extensively metabolized to $S$-LC $(95-98 \%)$ and, in a minor extent, to $R$-LC and OXC [5,6]. Unlike OXC, ESL appears to present a more favourable metabolic pathway, with a higher S/R licarbazepine enantiomeric ratio, without losing anticonvulsant potency [6,7].

To our knowledge, up to date, in spite of OXC to be used in the clinical practice for several years and ESL to be in final phase of clinical trials, few studies have investigated the systemic 
disposition of their licarbazepine enantiomers [6,8-11]. Furthermore, the differential pharmacokinetic disposition of $R$-LC and $S$-LC in brain, liver and kidney tissues remains unknown, contributing for that perhaps the lack of an economical chiral assay. In fact, only three chiral liquid chromatographic methods with ultraviolet detection (LC-UV) are reported in the literature for the quantification of licarbazepine enantiomers [8,12,13], and they were all developed under normal phase chromatographic columns with expensive mobile phases essentially composed of $n$-hexane. In addition, another chiral liquid chromatographic method with mass spectrometry detection (LC-MS) has also been referred to determine ESL and its metabolites $S$-LC, $R$-LC and OXC, but it was not yet completely described $[6,14]$.

Actually, the clinical development of a new drug always runs together with non-clinical studies, since for ethical aspects many experiments could not be performed in humans. Therefore, the availability of an accurate and easy-to-use LC method to quantify ESL and its metabolites in an appropriate experimental model will be important to complete the pharmacokinetic data that are arising from clinical trials. Thus, bearing in mind the metabolism specie-dependent of ESL and being mouse the most relevant specie to humans in this case [5,6,14], the purpose of this paper is to describe the first chiral reversed-phase LC-UV method developed and validated to simultaneous determination of ESL and its metabolites $S$-LC, $R$-LC and OXC in mouse plasma and brain, liver and kidney tissue homogenates.

\section{Experimental}

\subsection{Chemicals}

Standards of ESL (BIA 2-093, lot number 0000012976, $100 \%$ pure), S-LC (BIA 2-194, lot number PC020131B, 99.79\% pure), $R$-LC (BIA 2-195, lot number PC040414, 100\% pure), OXC (lot number 97.12.17, >98\% pure) and BIA 2-265 (lot number PC050704, 97.4\% pure) used as internal standard (I.S.), were kindly supplied by BIAL (Porto, Portugal) (Fig. 1). Methanol (LC grade, SDS), water milli-Q (LC grade, $>15 \mathrm{M} \Omega$, home-made), acetonitrile, ethyl acetate, sodium dihydrogen phosphate dihydrate, di-sodium hydrogen phosphate dehydrate and hydrochloric acid fuming 37\% were purchased from Merck KGaA (Darmstadt, Germany).

\subsection{Animal experiments}

Adult male CD-1 mice obtained from Harlan-Interfauna (Barcelona, Spain), weighing 30-35 g, were housed in local animal facilities with light $(12 \mathrm{~h}$ light/dark cycle) and temperature $\left(22 \pm 1{ }^{\circ} \mathrm{C}\right)$ controlled environment. A regular chow diet (4RF21, Mucedola, Italy) and tap water were available $a d$ libitum until the experimental procedures. Mice not subjected to any pharmacological treatment were used as a source of drug-free mouse plasma and brain, liver and kidney tissues, which were used as blank matrices in the validation studies. For that, blood samples were collected into heparinised tubes by decapitation preceded of cervical dislocation. The plasma was separated by centrifugation at $4000 \mathrm{rpm}$ for $10 \mathrm{~min}\left(4^{\circ} \mathrm{C}\right)$ and stored at $-30^{\circ} \mathrm{C}$ until use. After exsanguination, brain, liver and kidneys were quickly removed, weighed and then homogenised $\left(4 \mathrm{~mL} \mathrm{~g}^{-1}\right)$ in a $0.1 \mathrm{M}$ sodium phosphate buffer (pH 5). The tissue homogenates were centrifuged at $4800 \mathrm{rpm}$ for $15 \mathrm{~min}\left(4^{\circ} \mathrm{C}\right)$ and the supernatants were also stored at $-30^{\circ} \mathrm{C}$.

All animal experimentation was conducted in accordance with the European Directive (86/609/EEC) for the accommodation and care of laboratory animals and the experimental<smiles>CC(=O)O[C@H]1Cc2ccccc2N(C(N)=O)c2ccccc21</smiles>

ESL<smiles>NC(=O)N1c2ccccc2C[C@@H](O)c2ccccc21</smiles>

S-LC<smiles>NC(=O)N1c2ccccc2C[C@@H](O)c2ccccc21</smiles>

R-LC<smiles>NC(=O)N1c2ccccc2CC(=O)c2ccccc21</smiles>

OXC<smiles>NC(=O)N1c2ccccc2CC(CO)([N+](=O)[O-])c2ccccc21</smiles>

BIA 2-265 (I.S.)

Fig. 1. Chemical structures of eslicarbazepine acetate (ESL), $S$-licarbazepine ( $S$-LC), $R$-licarbazepine ( $R$-LC), oxcarbazepine (OXC) and BIA 2-265 used as internal standard (I.S.). 
procedures were approved by the Portuguese Veterinary General Division.

\subsection{Apparatus and chromatographic conditions}

LC analysis was performed on a BAS-480 Liquid Chromatograph equipped with a PM-80 pump, a Rheodyne manual injector with a $20 \mu \mathrm{L}$ loop, a BAS UV-116 UV-Vis detector, a BAS LC-22C Temperature Controller, a BAS DA-5 Chromatography Control and a Data System Interface (all from Bioanalytical Systems, West Lafayette, IN, USA). Data collection and integration were achieved by means of a BAS Chromgraph Control and Chromgraph Report software version 2.30 .

Chromatographic separation of all four drugs and I.S. was carried out at $30^{\circ} \mathrm{C}$ by isocratic elution with water/methanol $(88: 12, \mathrm{v} / \mathrm{v})$, at a flow rate of $0.7 \mathrm{~mL} \mathrm{~min}^{-1}$, on a LiChroCART 250-4 ChiraDex ( $\beta$-cyclodextrin, $5 \mu \mathrm{m})$ column protected by a LiChroCART 4-4 ChiraDex ( $\beta$-cyclodextrin, $5 \mu \mathrm{m}$ ) guard column purchased from Merck KGaA (Darmstadt, Germany). The mobile phase was filtered through a $0.45 \mu \mathrm{m}$ filter and degassed ultrasonically for $15 \mathrm{~min}$ before use. The injection volume was $20 \mu \mathrm{L}$ and the analytes were detected at $225 \mathrm{~nm}$.

\subsection{Stock solutions, calibration standards and quality control samples}

The stock solutions of ESL $\left(2 \mathrm{mg} \mathrm{mL}^{-1}\right), \quad S$-LC $\left(10 \mathrm{mg} \mathrm{mL}^{-1}\right), \quad R$-LC $\quad\left(10 \mathrm{mg} \mathrm{mL}^{-1}\right), \quad$ OXC $\quad\left(2 \mathrm{mg} \mathrm{mL}^{-1}\right)$ and I.S. (1 $\left.\mathrm{mg} \mathrm{mL}^{-1}\right)$ were prepared by dissolving appropriate amounts of each compound in acetonitrile. These solutions were adequately diluted with acetonitrile in order to give $S$-LC and $R$-LC $2 \mathrm{mg} \mathrm{mL}^{-1}$ solutions and ESL, $S$-LC, $R$-LC and OXC $200 \mu \mathrm{g} \mathrm{mL}^{-1}$ solutions. The prepared solutions were used appropriately to afford six combined spiking solutions of all four drugs with final concentrations of 10, 50, 500, 1000, 1500 and $2000 \mu \mathrm{g} \mathrm{mL}^{-1}$ for $S$-LC and $R$-LC, and 10, 20, 50, 100, 150 and $200 \mu \mathrm{g} \mathrm{mL}^{-1}$ for ESL and OXC. An I.S. working solution of $200 \mu \mathrm{g} \mathrm{mL}^{-1}$ was prepared by diluting appropriately the respective stock solution. All solutions were stored at $4{ }^{\circ} \mathrm{C}$ and protected from light for one month, except the I.S. working solution, which was prepared on each day of analysis.

Blank plasma and supernatants of the different tissue homogenates were spiked with the appropriate combined solutions to obtain five calibration standards containing ESL and OXC in the ranges of $0.4-8 \mu \mathrm{g} \mathrm{mL}^{-1}, 0.1-1.5 \mu \mathrm{g} \mathrm{mL}^{-1}$ and $0.1-2 \mu \mathrm{g} \mathrm{mL}^{-1}$ for plasma, brain and liver/kidney, respectively, and containing each licarbazepine enantiomer in the ranges of $0.4-80 \mu \mathrm{g} \mathrm{mL}^{-1}, 0.1-15 \mu \mathrm{g} \mathrm{mL}^{-1}$ and $0.1-20 \mu \mathrm{g} \mathrm{mL}^{-1}$ for the respective matrices previously referred. Quality control (QC) samples were prepared independently in the same biological matrices.

\subsection{Sample preparation and extraction procedure}

Aliquots of mouse plasma $(250 \mu \mathrm{L})$ were added to $750 \mu \mathrm{L}$ of $0.1 \mathrm{M}$ sodium phosphate buffer ( $\mathrm{pH}$ 5) spiked with $10 \mu \mathrm{L}$ of the I.S. working solution. The samples were vortexmixed and loaded into Waters (Milford, MA, USA) Oasis ${ }^{\circledR}$ hydrophilic-lipophilic balance (HLB) extraction cartridges (30 mg, $1 \mathrm{~mL}$ ), which were previously conditioned with $1 \mathrm{~mL}$ of methanol, $1 \mathrm{~mL}$ of acetonitrile and $1 \mathrm{~mL}$ of water/acetonitrile $(95: 5, \mathrm{v} / \mathrm{v})$. After sample elution, the loaded cartridges were submitted to $-30 \mathrm{kPa}$ and washed twice with $1 \mathrm{~mL}$ of water and twice with $1 \mathrm{~mL}$ of water/acetonitrile (95:5, v/v). After drying the sorbent under airflow for $5 \mathrm{~min}$, the analytes were eluted with $1 \mathrm{~mL}$ of ethyl acetate under gentle vacuum and then the cartridges were dried for $30 \mathrm{~s}$ at $-30 \mathrm{kPa}$. The eluates were evaporated to dryness under a nitrogen stream at $45^{\circ} \mathrm{C}$ and the residues reconstituted in $100 \mu \mathrm{L}$ of LC mobile phase, vortexed for approximately $30 \mathrm{~s}$ and placed in an ultrasonic bath at room temperature for approximately $1 \mathrm{~min}$. Following this, the reconstituted extracts were transferred to $0.22 \mu \mathrm{m}$ Spin$\mathrm{X}$ centrifugal filters, centrifuged at $13,400 \mathrm{rpm}$ for $2 \mathrm{~min}$ and $20 \mu \mathrm{L}$ of the final filtered samples were injected onto the LC system.

The supernatant samples of tissue (brain, liver and kidney) homogenates were thawed, centrifuged (13,400 rpm for $20 \mathrm{~min}$ ) a second time to give clear supernatants and $1 \mathrm{~mL}$ was used for analysis after spiking with $10 \mu \mathrm{L}$ of the I.S. working solution. Afterwards, the analytes of supernatant samples were extracted by a solid-phase extraction (SPE) procedure as described for plasma samples, but with some differences in the washing steps and vacuum conditions $(-40 \mathrm{kPa})$. As brain, liver and kidney matrices are more complexes than plasma, the loaded cartridges were washed with $1 \mathrm{~mL}$ of water and $1 \mathrm{~mL}$ of water/acetonitrile $(95: 5, \mathrm{v} / \mathrm{v})$ for three or four times, in brain samples or in liver and kidney samples, respectively. The corresponding eluates were processed in the same way as those obtained from plasma samples.

\subsection{Method validation}

The method was validated according to the general recommendations published in the last few years with regard to bioanalytical method validation and acceptance criteria for validation parameters: selectivity, linearity, sensitivity, precision, accuracy, sample dilution, recovery and stability $[15,16]$.

Selectivity was studied investigating the absence of endogenous interferences from extracts of blank samples (plasma and supernatant of brain, liver and kidney homogenates) of six different mice.

To evaluate the linearity of the analytical method, calibration curves were prepared using five calibration standards and assayed on 5 separate days $(n=5)$. The calibration curves were constructed by plotting drug/I.S. peak height ratio as a function of the respective concentrations. The data were subjected to a weighted linear regression analysis using $1 / x^{2}$ as weighting factor, which was chosen taking the plots and the sums of absolute percentage relative error into account [17]. The limit of quantification (LOQ), defined as the lowest concentration of the calibration curve that can be measured with acceptable precision and accuracy, was established using five extracted samples $(n=5)$. The limit of detection (LOD), defined as the lowest con- 
centration that can be distinguished from the noise level, was determined after successive dilutions of the lowest calibration standard and it was established by instrumental evaluation taking into account a signal-to-noise ratio of three.

Intra and interday precision and accuracy were assessed by QC samples, using replicates $(n=5)$ at three concentration levels (low, medium and high) representative of the calibration range. The acceptance criterion for intra and interday precision (expressed as percentage of coefficient of variation, \%CV) was a CV no more than $15 \%$ (or $20 \%$ in the LOQ) and for intra and interday accuracy (expressed as percentage of deviation from nominal value, $\%$ bias) was a bias within $\pm 15 \%$ (or $\pm 20 \%$ in the LOQ).
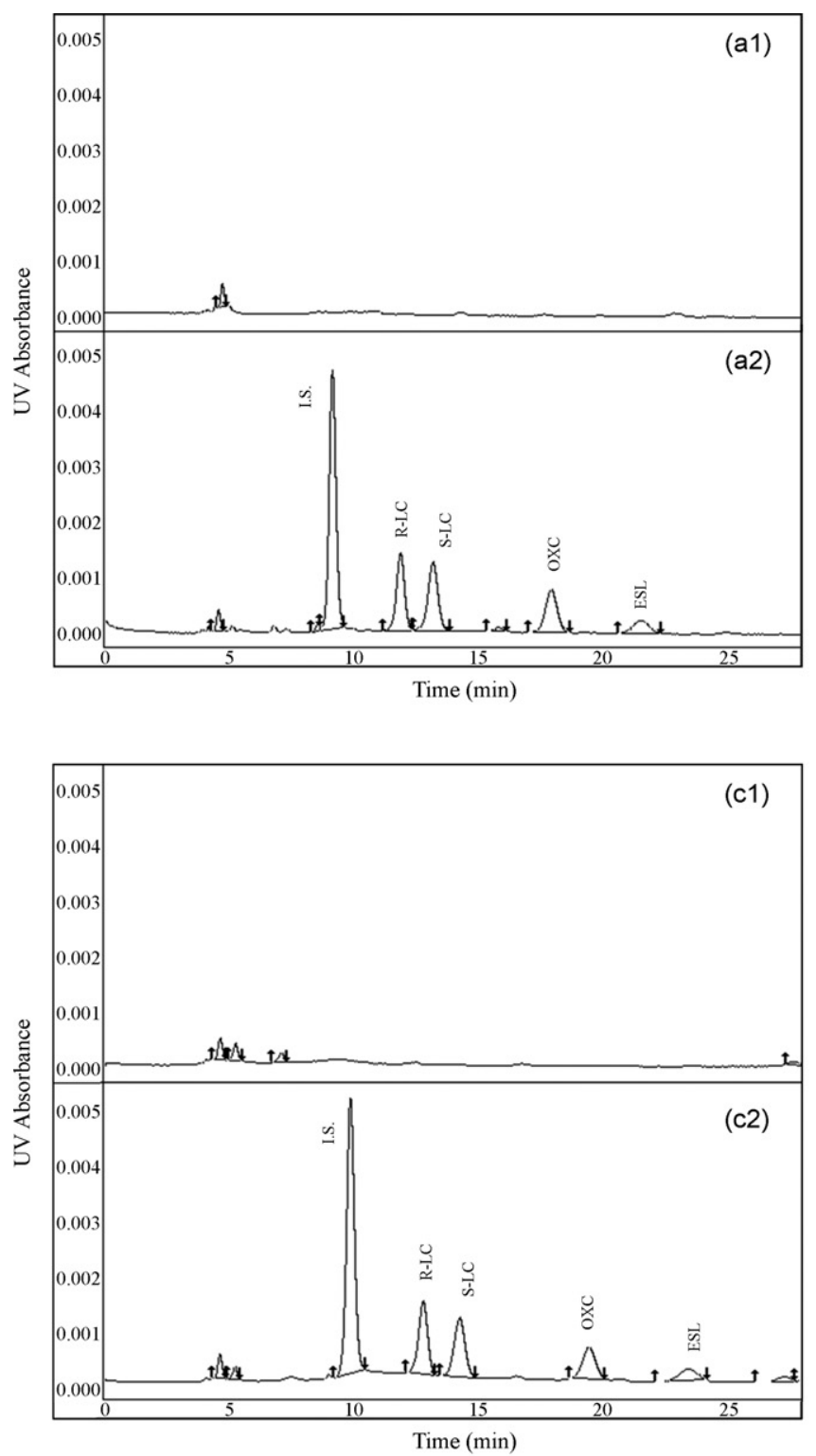

The dilution effect (1:10) was investigated in plasma and in supernatant of liver and kidney tissue homogenates with appropriate QC samples $\left(40 \mu \mathrm{g} \mathrm{mL}^{-1}\right.$ for ESL and OXC and $400 \mu \mathrm{g} \mathrm{mL}^{-1}$ for licarbazepine enantiomers in plasma; $10 \mu \mathrm{g} \mathrm{mL}^{-1}$ for ESL and OXC and $100 \mu \mathrm{g} \mathrm{mL}^{-1}$ for licarbazepine enantiomers in liver and kidney) to ensure that samples exceeding the highest concentration of the calibration range could be appropriately diluted with the respective blank matrix and accurately quantified. The precision and accuracy of diluted samples were determined in both intra and interday assays $(n=5)$.

Drug relative recoveries were calculated at three concentration levels by comparing the drug/I.S. peak height ratios of
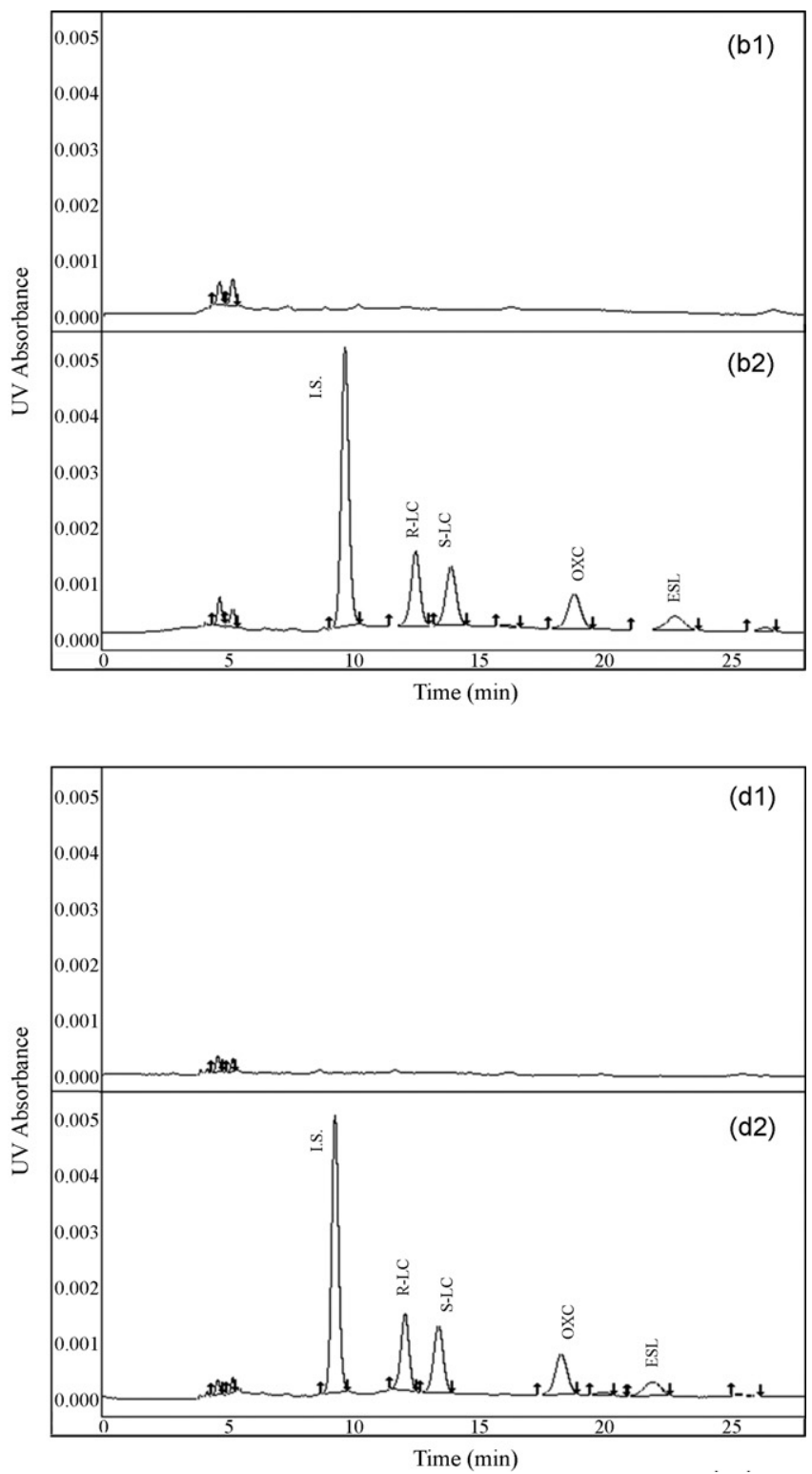

Fig. 2. Typical LC-UV chromatograms of extracted mouse samples. (a1) Blank and (a2) spiked plasma with I.S. ( $\left.8 \mu \mathrm{g} \mathrm{mL} \mathrm{L}^{-1}\right), R$-LC and $S$-LC $\left(2 \mu \mathrm{g} \mathrm{mL} \mathrm{m}^{-1}\right), \mathrm{OXC}^{-}$and $\operatorname{ESL}\left(0.8 \mu \mathrm{g} \mathrm{mL}^{-1}\right)$; (b1) blank and (b2) spiked supernatant of brain homogenate with I.S. $\left(2 \mu \mathrm{g} \mathrm{mL}^{-1}\right), R$-LC and $S$-LC $\left(0.5 \mu \mathrm{g} \mathrm{mL}{ }^{-1}\right), \mathrm{OXC}$ and ESL $(0.2 \mu \mathrm{g} \mathrm{mL}-1)$; (c1) blank and (c2) spiked supernatant of liver homogenate with I.S. $\left(2 \mu \mathrm{g} \mathrm{mL}^{-1}\right), R$-LC and $S$-LC $\left(0.5 \mu \mathrm{g} \mathrm{mL}^{-1}\right), \mathrm{OXC}$ and ESL $\left(0.2 \mu \mathrm{g} \mathrm{mL}{ }^{-1}\right)$; (d1) blank and (d2) spiked supernatant of kidney homogenate with I.S. $\left(2 \mu \mathrm{g} \mathrm{mL}^{-1}\right), R$-LC and $S$-LC $\left(0.5 \mu \mathrm{g} \mathrm{mL}^{-1}\right)$, OXC and ESL $\left(0.2 \mu \mathrm{g} \mathrm{mL} \mathrm{m}^{-1}\right)$. 
extracted samples with the corresponding ratios obtained with non-extracted standards $(n=5)$. The I.S. absolute recovery was also determined by calculating the I.S. peak height ratio of extracted samples and non-extracted standards $(n=5)$.

The stability of ESL and its metabolites was assessed in all matrices, at two concentration levels $\left(0.8 \mu \mathrm{g} \mathrm{mL}^{-1}\right.$ and $4 \mu \mathrm{g} \mathrm{mL}^{-1}$ for ESL and OXC and $2 \mu \mathrm{g} \mathrm{mL}^{-1}$ and $40 \mu \mathrm{g} \mathrm{mL}^{-1}$ for licarbazepine enantiomers in plasma; $0.2 \mu \mathrm{g} \mathrm{mL}^{-1}$ and $1 \mu \mathrm{g} \mathrm{mL}^{-1}$ for ESL and OXC and $0.5 \mu \mathrm{g} \mathrm{mL}^{-1}$ and $10 \mu \mathrm{g} \mathrm{mL}^{-1}$ for licarbazepine enantiomers in brain, liver and kidney samples), by $24 \mathrm{~h}$ at $4{ }^{\circ} \mathrm{C}$ and 30 days at $-30{ }^{\circ} \mathrm{C}$ to simulate sample handling and storage time in the freezer before analysis $(n=5)$. Stability was assessed comparing the QC samples analysed before (reference samples) and after being exposed to the conditions for stability assessment (stability samples), considering as acceptable stability criterion the stability sample/reference sample ratio of $85-115 \%$.

\section{Results and discussion}

\subsection{Method development and selectivity}

Since cyclodextrins have been widely used as chiral selectors [18] and a LiChroCART 250-4 ChiraDex ( $\beta$-cyclodextrin, $5 \mu \mathrm{m})$ column has been used to separate ESL metabolites $(S$ LC, $R$-LC and OXC) by LC-MS using water/methanol (80:20, $\mathrm{v} / \mathrm{v})$ at a flow rate of $0.8 \mathrm{~mL} \mathrm{~min}^{-1}[6,14]$, these chromatographic conditions coupled to UV detection at $210 \mathrm{~nm}$ [8] were predefined for the first experiments. However, under these conditions, the resolution between $R$-LC and $S$-LC was not enough. Thus, after extensive experiments with standard solu- tions, the chromatographic separation of the target analytes was attained with a mixture of water/methanol $(88: 12$, v/v), at a flow rate of $0.7 \mathrm{~mL} \mathrm{~min}^{-1}$, on a LiChroCART 250-4 ChiraDex $(\beta$ cyclodextrin, $5 \mu \mathrm{m}$ ) column protected by a LiChroCART 4-4 ChiraDex ( $\beta$-cyclodextrin, $5 \mu \mathrm{m}$ ) guard column, at $30^{\circ} \mathrm{C}$. Then, the flowing step was the selection of an adequate I.S., chemically related to the analytes of interest. As starting point was assayed the 10,11-dihydrocarbamazepine already used as I.S. $[6,14]$. However, this compound was shown to be inadequate because the chromatographic run time would increase significantly. Therefore, several compounds with chemical structures similar to those of the analytes, provided by BIAL Laboratories, were tested for potential use as I.S. Among them, BIA 2-265 was selected by its appropriate retention time and sharpened symmetric peak, taking into account at the same time that it is not a metabolite of ESL.

Given that, qualitatively, ESL and OXC have a similar metabolism, the SPE procedure here developed to extract ESL and its metabolites from mouse samples was based on the methods presented by Hainzl et al. [14] and Mandrioli et al. [19]. The optimization of the extraction procedure was achieved in Waters (Milford, MA, USA) Oasis ${ }^{\circledR}$ HLB cartridges ( $30 \mathrm{mg}, 1 \mathrm{~mL}$ ) with the experimental conditions mentioned in Section 2.5.

The chiral separation of licarbazepine enantiomers, OXC, ESL and I.S. in mouse plasma and tissue (brain, liver and kidney) homogenates was achieved successfully using the chromatographic conditions and the SPE procedure developed. Under these conditions, the last-eluting compound was ESL and the order of elution was I.S., $R$-LC, $S$-LC, OXC and ESL. Typical chromatograms of extracts from blank and spiked samples of mouse plasma and tissue homogenates are shown in Fig. 2. The

Table 1

Calibration curve parameters ${ }^{\mathrm{a}}$ for ESL, $S$-LC, $R$-LC and OXC in mouse plasma and supernatant of brain, liver and kidney homogenates $(n=5)$

\begin{tabular}{|c|c|c|c|c|}
\hline Matrix/drug & Calibration standards $\left(\mu \mathrm{g} \mathrm{mL}^{-1}\right)$ & Slope $(b)$ & Intercept $(a)$ & Determination coefficient $\left(r^{2}\right)$ \\
\hline \multicolumn{5}{|l|}{ Plasma } \\
\hline ESL & $0.4,0.8,2,4,8$ & 0.0578 & 0.0000 & 0.996 \\
\hline$S$-LC & $0.4,2,20,40,80$ & 0.1201 & -0.0004 & 0.998 \\
\hline$R$-LC & $0.4,2,20,40,80$ & 0.1425 & -0.0062 & 0.998 \\
\hline $\mathrm{OXC}$ & $0.4,0.8,2,4,8$ & 0.1786 & 0.0069 & 0.996 \\
\hline \multicolumn{5}{|l|}{ Brain } \\
\hline ESL & $0.1,0.2,0.5,1,1.5$ & 0.2295 & -0.0004 & 0.998 \\
\hline$S$-LC & $0.1,0.5,5,10,15$ & 0.4127 & 0.0016 & 0.999 \\
\hline$R$-LC & $0.1,0.5,5,10,15$ & 0.5178 & 0.0029 & 0.999 \\
\hline $\mathrm{OXC}$ & $0.1,0.2,0.5,1,1.5$ & 0.6460 & -0.0071 & 0.998 \\
\hline \multicolumn{5}{|l|}{ Liver } \\
\hline ESL & $0.1,0.2,0.5,1,2$ & 0.2199 & -0.0008 & 0.998 \\
\hline$S$-LC & $0.1,0.5,5,10,20$ & 0.4186 & 0.0009 & 0.999 \\
\hline$R$-LC & $0.1,0.5,5,10,20$ & 0.5236 & -0.0030 & 0.999 \\
\hline $\mathrm{OXC}$ & $0.1,0.2,0.5,1,2$ & 0.6726 & -0.0052 & 0.998 \\
\hline \multicolumn{5}{|l|}{ Kidney } \\
\hline ESL & $0.1,0.2,0.5,1,2$ & 0.2025 & -0.0004 & 0.999 \\
\hline$S$-LC & $0.1,0.5,5,10,20$ & 0.4084 & -0.0013 & 0.999 \\
\hline$R$-LC & $0.1,0.5,5,10,20$ & 0.4952 & -0.0018 & 0.999 \\
\hline $\mathrm{OXC}$ & $0.1,0.2,0.5,1,2$ & 0.6026 & -0.0056 & 0.997 \\
\hline
\end{tabular}

${ }^{a}$ Equation of the calibration curve $y=b x+a$, where $x$ is the drug concentration, expressed in $\mu \mathrm{g} \mathrm{mL}{ }^{-1}$, and $y$ is the drug to I.S. peak height ratio, expressed in arbitrary height units. 
chromatograms demonstrate that in all drug-free matrices no endogenous compounds are interfering at the retention times of the I.S. or the analytes.

\subsection{Calibration curve}

The calibration curves were linear for ESL and OXC over the concentration ranges $0.4-8 \mu \mathrm{g} \mathrm{mL}^{-1}$ in mouse plasma, $0.1-1.5 \mu \mathrm{g} \mathrm{mL}^{-1}$ in supernatant of brain homogenate and $0.1-2 \mu \mathrm{g} \mathrm{mL}^{-1}$ in supernatants of liver and kidney homogenates, and for each licarbazepine enantiomer in the ranges of $0.4-80 \mu \mathrm{g} \mathrm{mL}^{-1}, 0.1-15 \mu \mathrm{g} \mathrm{mL}^{-1}$ and $0.1-20 \mu \mathrm{g} \mathrm{mL}^{-1}$ in plasma, brain and liver/kidney, respectively. The calibration curves were subjected to weighted linear regression analysis and the respective parameters are shown in Table 1, where the determination coefficients demonstrate good linearity for all analytes in all studied matrices $\left(r^{2} \geq 0.996\right)$. The lowest calibration standard corresponded to the LOQ $\left(0.4 \mu \mathrm{g} \mathrm{mL}^{-1}\right.$ or $0.1 \mu \mathrm{g} \mathrm{mL}^{-1}$ using $250 \mu \mathrm{L}$ of plasma or $1 \mathrm{~mL}$ of supernatant of tissue homogenates, respectively), which could be measured with acceptable precision and accuracy $(\leq 20 \%)$. The LOD was $0.1 \mu \mathrm{g} \mathrm{mL}^{-1}$ for ESL and $0.04 \mu \mathrm{g} \mathrm{mL}^{-1}$ for OXC, $S$-LC and $R$ -

Table 2

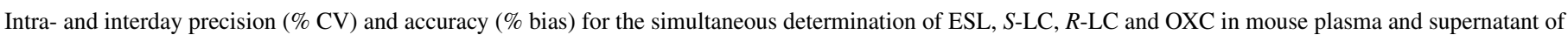
brain, liver and kidney homogenates $(n=5)$

\begin{tabular}{|c|c|c|c|c|c|c|c|c|}
\hline \multirow[t]{3}{*}{$C_{\text {Nominal }^{\mathrm{a}}}{ }^{\mathrm{a}}$} & \multicolumn{8}{|l|}{ Assay } \\
\hline & \multicolumn{4}{|c|}{ Intraday } & \multicolumn{4}{|c|}{ Interday } \\
\hline & $\% \mathrm{CV}$ & $\%$ Bias & $\% \mathrm{CV}$ & $\%$ Bias & $\% \mathrm{CV}$ & $\%$ Bias & $\% \mathrm{CV}$ & $\%$ Bias \\
\hline Plasma & \multicolumn{2}{|l|}{ ESL } & \multicolumn{2}{|l|}{ OXC } & \multicolumn{2}{|l|}{ ESL } & \multicolumn{2}{|l|}{$\mathrm{OXC}$} \\
\hline 0.4 & 6.06 & -3.53 & 4.66 & -2.49 & 3.21 & -2.59 & 4.17 & -2.57 \\
\hline 4 & 2.05 & -0.300 & 2.13 & 0.340 & 2.60 & 0.0400 & 3.15 & 0.180 \\
\hline \multirow[t]{2}{*}{8} & 1.99 & -2.32 & 2.37 & -1.73 & 3.49 & -0.880 & 3.69 & -1.34 \\
\hline & \multicolumn{2}{|l|}{$S$-LC } & \multicolumn{2}{|l|}{$R$-LC } & \multicolumn{2}{|l|}{$S$-LC } & \multicolumn{2}{|l|}{$R-\mathrm{LC}$} \\
\hline 0.4 & 3.52 & -0.840 & 3.14 & -0.810 & 5.32 & -1.31 & 3.76 & -0.980 \\
\hline 40 & 2.73 & 0.250 & 2.70 & 0.730 & 3.40 & -1.26 & 3.55 & -0.350 \\
\hline 80 & 1.78 & -2.77 & 1.67 & -2.50 & 4.94 & -2.60 & 5.03 & -1.85 \\
\hline Brain & \multicolumn{2}{|l|}{ ESL } & \multicolumn{2}{|l|}{ OXC } & \multicolumn{2}{|l|}{ ESL } & \multicolumn{2}{|l|}{ OXC } \\
\hline 0.1 & 7.63 & 0.100 & 4.21 & 1.62 & 11.6 & -1.81 & 5.15 & 1.53 \\
\hline 1 & 3.84 & -2.06 & 2.82 & -0.990 & 5.94 & -3.00 & 6.38 & -1.29 \\
\hline \multirow[t]{2}{*}{1.5} & 5.62 & 1.50 & 5.10 & 2.72 & 5.81 & 0.370 & 6.94 & 2.27 \\
\hline & \multicolumn{2}{|l|}{$S$-LC } & \multicolumn{2}{|l|}{$R$-LC } & \multicolumn{2}{|l|}{$S$-LC } & \multicolumn{2}{|l|}{$R$-LC } \\
\hline 0.1 & 4.93 & 0.200 & 4.31 & -0.0100 & 9.62 & -0.0200 & 9.79 & -0.200 \\
\hline 10 & 3.89 & 0.560 & 3.94 & 0.360 & 4.97 & 0.510 & 4.83 & 0.340 \\
\hline 15 & 5.72 & -0.130 & 5.77 & -0.140 & 4.57 & 0.0900 & 4.50 & 0.150 \\
\hline Liver & \multicolumn{2}{|l|}{ ESL } & \multicolumn{2}{|l|}{ OXC } & \multicolumn{2}{|l|}{ ESL } & \multicolumn{2}{|l|}{$\mathrm{OXC}$} \\
\hline 0.1 & 3.76 & -1.37 & 4.69 & 0.500 & 5.93 & 0.950 & 4.67 & 1.44 \\
\hline 1 & 1.61 & -3.79 & 2.94 & -1.57 & 2.12 & 0.650 & 3.73 & 1.01 \\
\hline \multirow[t]{2}{*}{2} & 3.49 & 0.0100 & 4.01 & 0.160 & 2.70 & -0.590 & 1.01 & 0.760 \\
\hline & $S$-LC & & $R$-LC & & $S$-LC & & $R$-LC & \\
\hline 0.1 & 4.20 & -0.0100 & 5.73 & -0.240 & 4.76 & -0.110 & 5.96 & -0.210 \\
\hline 10 & 1.80 & 0.570 & 1.88 & 0.460 & 3.20 & 1.15 & 3.09 & 1.29 \\
\hline 20 & 1.87 & -0.960 & 1.88 & -0.930 & 3.49 & 0.0500 & 3.45 & 0.150 \\
\hline Kidney & ESL & & $\mathrm{OXC}$ & & ESL & & $\mathrm{OXC}$ & \\
\hline 0.1 & 7.71 & 1.94 & 9.70 & 3.84 & 8.89 & 0.990 & 7.17 & 2.82 \\
\hline 1 & 1.75 & 3.35 & 3.27 & 3.30 & 3.32 & 1.21 & 5.65 & 0.690 \\
\hline 2 & 2.85 & -0.170 & 4.16 & 1.04 & 2.95 & -0.0300 & 2.95 & 1.79 \\
\hline & $S$-LC & & $R-\mathrm{LC}$ & & $S$-LC & & $R$-LC & \\
\hline 0.1 & 7.01 & 0.350 & 4.13 & 0.440 & 10.4 & 0.390 & 10.1 & 0.310 \\
\hline 10 & 3.18 & 1.62 & 3.14 & 1.85 & 3.46 & 1.26 & 3.44 & 1.13 \\
\hline 20 & 4.01 & 1.07 & 4.07 & 0.420 & 2.58 & -0.220 & 2.54 & -1.04 \\
\hline
\end{tabular}

${ }^{\text {a }}$ Nominal concentration $\left(\mu \mathrm{g} \mathrm{mL}^{-1}\right)$. 
LC in plasma, and $0.025 \mu \mathrm{g} \mathrm{mL}^{-1}$ for ESL and $0.01 \mu \mathrm{g} \mathrm{mL}^{-1}$ for its metabolites in supernatant of mouse tissue homogenates.

\subsection{Precision and accuracy}

The data presented in Table 2 show the intra and interday precision and accuracy for plasma and supernatant of tissue homogenates. The overall intra and interday precision $(\% \mathrm{CV})$ is within $11.6 \%$ and the accuracy (\%bias) varied from -3.79 to $3.84 \%$. These data demonstrate that both precision and accuracy are within the acceptable limits in all matrices, being the method precise and accurate to determine these drugs from mouse plasma, brain, liver and kidney samples.

The sample dilution (1:10) was also investigated intra and interday in plasma, liver and kidney samples and showed to be precise $(\mathrm{CV}<5.0 \%)$ and accurate (bias ranged from -2.94 to $-1.35 \%$ ) in the studied biological matrices. These results revealed that a 10 -fold dilution with blank matrix can be rightly applied if the concentration of a trial sample exceeds the highest concentration of the calibration curve.

\subsection{Recovery}

The relative drug recoveries from plasma and tissue homogenates were estimated and presented in Table 3. The mean relative recoveries, taking the ESL and its metabolites into account in all matrices, ranged from 89.1 to $102 \%$. As shown in Table 3, the values of CV were relatively low, which suggests consistent average recoveries over the evaluated concentration range. The absolute recovery of the I.S. in mouse plasma and tissue homogenates was also evaluated, with values between $73.5 \%$ and $89.1 \%$ and $\mathrm{CV}$ within $5.77 \%$.

\subsection{Stability}

From drug stability data obtained in plasma and mouse tissue homogenates for ESL and its metabolites no significant loss was observed when spiked samples were stored for 30 days at $-30{ }^{\circ} \mathrm{C}$, but ESL showed instability in plasma and kidney samples when stored at $4{ }^{\circ} \mathrm{C}$ for $24 \mathrm{~h}$. However, that important loss detected for ESL at $4{ }^{\circ} \mathrm{C}$ for $24 \mathrm{~h}$ in plasma and kidney samples is not worrying, since after dissection the mouse samples remain on ice no more than few minutes until storage at $-30{ }^{\circ} \mathrm{C}$. On the other hand, the preclinical and clinical studies have demonstrated that the prodrug ESL is rapidly metabolised and appears below the limit of quantification (BLQ) at all time points post-dose at all studied dose levels $[5-7,14]$.

\subsection{Method application}

The application of the proposed LC-UV assay to real samples was also demonstrated following a single oral administration of ESL $500 \mathrm{mg} \mathrm{kg}^{-1}$. The samples of interest (plasma, brain, liver and kidneys) were taken at $0.5 \mathrm{~h}$ post-dose and immediately processed as indicated in Sections 2.2 and 2.5. As indicated in Fig. 3,
Table 3

Relative recoveries (\%) of ESL, $S$-LC, $R$-LC and OXC in mouse plasma and supernatant of brain, liver and kidney homogenates

\begin{tabular}{|c|c|c|c|c|c|}
\hline \multirow[t]{2}{*}{$C_{\text {Nominal }}{ }^{\mathrm{a}}$} & \multirow[t]{2}{*}{$n^{\mathrm{b}}$} & \multicolumn{4}{|c|}{ Relative recovery $(\%)$} \\
\hline & & Mean & $\% \mathrm{CV}$ & Mean & $\% \mathrm{CV}$ \\
\hline \multicolumn{2}{|l|}{ Plasma } & \multicolumn{2}{|l|}{ ESL } & \multicolumn{2}{|l|}{$\mathrm{OXC}$} \\
\hline 0.4 & 5 & 95.1 & 3.57 & 92.1 & 5.43 \\
\hline 4 & 5 & 98.0 & 2.30 & 96.7 & 2.06 \\
\hline \multirow[t]{3}{*}{8} & 5 & 95.1 & 2.86 & 91.0 & 3.37 \\
\hline & 15 & 96.1 & 3.26 & 93.3 & 4.64 \\
\hline & & \multicolumn{2}{|l|}{$S$-LC } & \multicolumn{2}{|l|}{$R-\mathrm{LC}$} \\
\hline 0.4 & 5 & 103 & 4.27 & 100 & 2.84 \\
\hline 40 & 5 & 105 & 2.13 & 106 & 2.30 \\
\hline \multirow[t]{2}{*}{80} & 5 & 98.2 & 2.69 & 96.5 & 3.01 \\
\hline & 15 & 102 & 4.23 & 101 & 4.79 \\
\hline Brain & & \multicolumn{2}{|l|}{ ESL } & \multicolumn{2}{|l|}{$\mathrm{OXC}$} \\
\hline 0.1 & 5 & 90.3 & 7.05 & 87.8 & 3.60 \\
\hline 1 & 5 & 95.2 & 5.90 & 87.4 & 6.60 \\
\hline \multirow[t]{3}{*}{1.5} & 5 & 97.1 & 2.30 & 92.7 & 2.39 \\
\hline & 15 & 94.2 & 6.18 & 89.3 & 5.22 \\
\hline & & \multicolumn{2}{|l|}{$S$-LC } & \multicolumn{2}{|l|}{$R$-LC } \\
\hline 0.1 & 5 & 95.7 & 3.32 & 98.8 & 6.10 \\
\hline 10 & 5 & 94.7 & 5.77 & 95.7 & 5.80 \\
\hline \multirow[t]{2}{*}{15} & 5 & 98.6 & 3.13 & 99.3 & 2.91 \\
\hline & 15 & 96.3 & 4.54 & 97.9 & 5.37 \\
\hline Liver & & \multicolumn{2}{|l|}{ ESL } & \multicolumn{2}{|l|}{$\mathrm{OXC}$} \\
\hline 0.1 & 5 & 97.7 & 8.40 & 97.5 & 4.23 \\
\hline 1 & 5 & 96.1 & 2.53 & 88.7 & 3.79 \\
\hline \multirow[t]{3}{*}{2} & 5 & 99.2 & 4.74 & 97.6 & 4.87 \\
\hline & 15 & 97.7 & 5.92 & 94.6 & 6.18 \\
\hline & & \multicolumn{2}{|l|}{$S$-LC } & \multicolumn{2}{|l|}{$R-\mathrm{LC}$} \\
\hline 0.1 & 5 & 97.4 & 6.85 & 95.5 & 5.21 \\
\hline 10 & 5 & 97.1 & 3.49 & 97.9 & 3.39 \\
\hline \multirow[t]{2}{*}{20} & 5 & 97.6 & 3.54 & 98.1 & 3.46 \\
\hline & 15 & 97.4 & 4.89 & 97.2 & 4.27 \\
\hline Kidney & & \multicolumn{2}{|l|}{ ESL } & \multicolumn{2}{|l|}{$\mathrm{OXC}$} \\
\hline 0.1 & 5 & 93.2 & 4.53 & 90.4 & 3.48 \\
\hline 1 & 5 & 93.9 & 3.16 & 88.0 & 2.66 \\
\hline \multirow[t]{3}{*}{2} & 5 & 91.6 & 3.30 & 88.9 & 2.19 \\
\hline & 15 & 92.9 & 3.85 & 89.1 & 3.04 \\
\hline & & $S$-LC & & $R$-LC & \\
\hline 0.1 & 5 & 98.3 & 2.18 & 93.3 & 2.89 \\
\hline 10 & 5 & 92.6 & 3.42 & 93.1 & 3.45 \\
\hline 20 & 5 & 96.0 & 2.01 & 96.3 & 1.98 \\
\hline & 15 & 95.6 & 3.56 & 94.2 & 3.21 \\
\hline
\end{tabular}

a Nominal concentration $\left(\mu \mathrm{g} \mathrm{mL}^{-1}\right)$.

b $n$, number of samples.

ESL metabolites were successful separated in mouse plasma and supernatant of brain, liver and kidney tissue homogenates, despite the low and high concentrations of $R$-LC and $S$-LC generated in vivo. However, $R$-LC only appeared in measurable amounts in liver (Fig. 3c) and, in agreement with previous studies [14], the parent compound was not detected. 

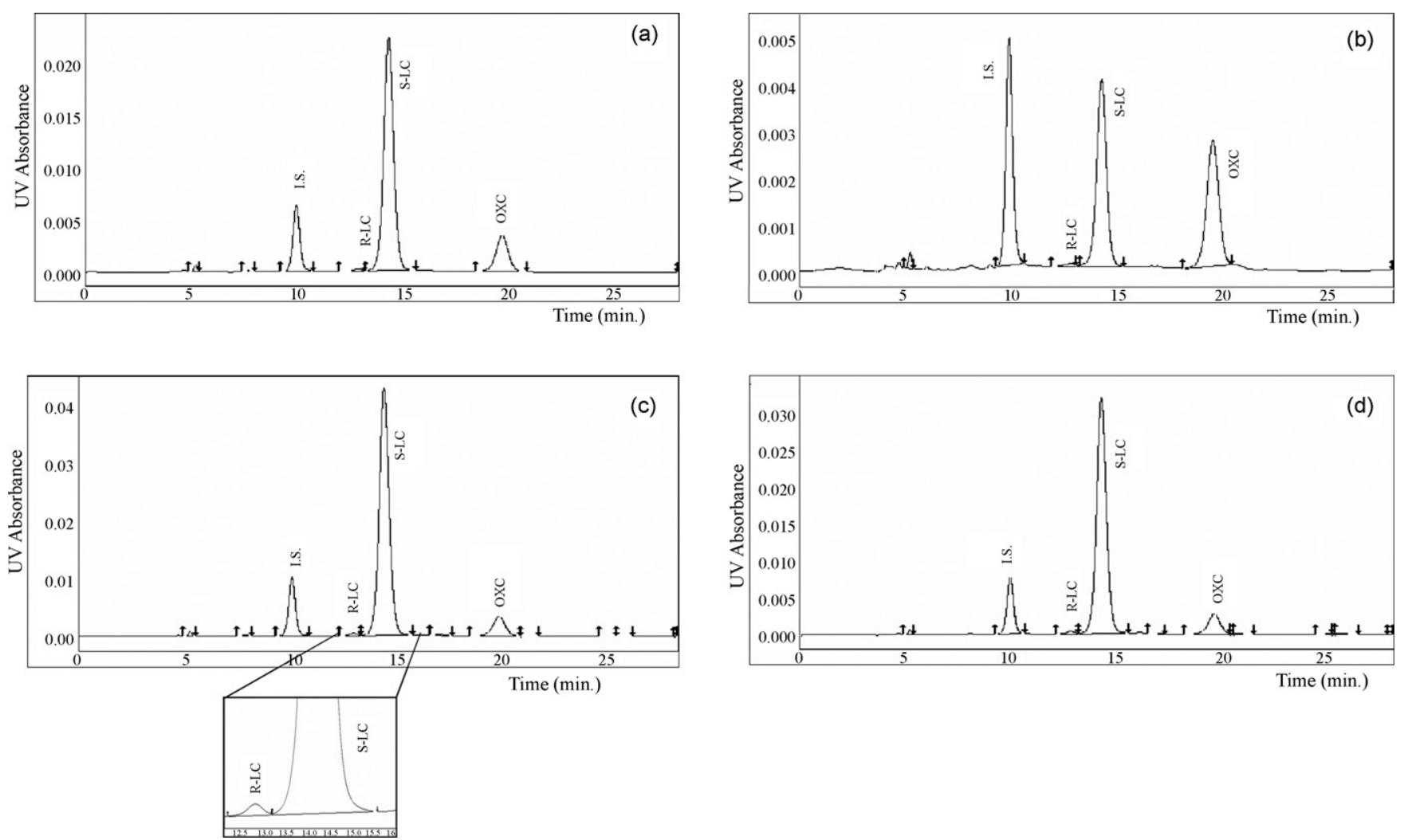

Fig. 3. Chromatograms obtained from mouse samples at $0.5 \mathrm{~h}$ after oral administration of ESL $500 \mathrm{mg} \mathrm{kg}^{-1}$. The peaks correspond to the following concentrations: (a) $R$-LC (BLQ), $S$-LC $\left(31.0 \mu \mathrm{g} \mathrm{mL}^{-1}\right)$ and OXC ( $\left.3.26 \mu \mathrm{g} \mathrm{mL}^{-1}\right)$ in plasma; (b) $R$-LC (BLQ), $S$-LC $\left(1.91 \mu \mathrm{g} \mathrm{mL}^{-1}\right)$ and OXC $\left(0.88 \mu \mathrm{g} \mathrm{mL}{ }^{-1}\right)$ in brain supernatant; (c) $R$-LC $\left(0.16 \mu \mathrm{g} \mathrm{mL}^{-1}\right), S$-LC $\left(9.61 \mu \mathrm{g} \mathrm{mL}^{-1}\right)$ and OXC $\left(0.48 \mu \mathrm{g} \mathrm{mL}^{-1}\right)$ in liver supernatant; (d) $R$-LC (BLQ), $S$-LC $\left(8.73 \mu \mathrm{g} \mathrm{mL}{ }^{-1}\right) \mathrm{and} \mathrm{OXC}\left(0.57 \mu \mathrm{g} \mathrm{mL}^{-1}\right)$ in kidney supernatant.

\section{Conclusion}

Up to date, none LC-UV method was published to quantify ESL and its metabolites, only an LC-MS assay is available $[6,14]$. Thus, this paper describes the first chiral reversed-phase LC-UV-SPE method fully validated to quantify ESL, $R$-LC, $S$ LC and OXC in mouse plasma and tissue homogenates. The method seems to be precise and accurate and the SPE procedure developed gives good results in terms of selectivity, reproducibility and extraction yield. Compared to the literature chiral methods for analysis of $R$-LC and $S$-LC $[8,12,13]$, the assay presented here offers as major advantages the very simple and economical chromatographic conditions with a mobile phase essentially composed of water.

Our results clearly evidenced, by the corresponding retention time values, that $S$-LC forms more stable transient diastereomeric complexes than $R$-LC with the ChiraDex stationary phase, and thus, the $S$-LC elution occurs later than that for $R$-LC. Hence, taking into account the unique properties of cyclodextrins to generate hydrophobic cavities with hydrophilic exterior faces in aqueous solutions, the chiral discrimination between $R$ LC and $S$-LC will be due to the differences in their steric fit in the chiral cavities and their ability to establish hydrogen bonds. However, other intermolecular interactions may contribute for the enantiomeric resolution $[18,20]$.
The method was validated in mouse tissue samples given that the preclinical and clinical data already available for these compounds indicate that, among the small laboratory animals, the mouse model showed similar metabolic pathways to humans $[5,6,14]$. Consequently, plasma, brain, liver and kidney matrices were selected, since they represent the main body tissues of interest to perform pharmacokinetic studies with CNS-active drugs. In conclusion, this LC-UV method allows the reliable and simultaneous determination of ESL metabolites in mice, supporting future non-clinical studies in order to clarify the pharmacokinetic data that are progressively arising from man.

\section{Acknowledgements}

This work was supported by Fundação para a Ciência e a Tecnologia, Programa POCTI (SFRH/BD/12694/2003), Portugal and by BIAL, Portugal.

\section{References}

[1] L. Almeida, P. Soares-da-Silva, Neurotherapeutics 4 (2007) 88

[2] J. Benes, A. Parada, A.A. Figueiredo, P.C. Alves, A.P. Freitas, D.A. Learmonth, R.A. Cunha, J. Garret, P. Soares-da-Silva, J. Med. Chem. 42 (1999) 2582.

[3] T.W. May, E. Korn-Merker, B. Rambeck, Clin. Pharmacokinet. 42 (2003) 1023. 
[4] G. Flesch, Clin. Drug Invest. 24 (2004) 185.

[5] L. Almeida, P. Soares-da-Silva, J. Clin. Pharmacol. 44 (2004) 906.

[6] L. Almeida, A. Falcão, J. Maia, D. Mazur, M. Gellert, P. Soares-da-Silva, J. Clin. Pharmacol. 45 (2005) 1062.

[7] L. Almeida, P. Soares-da-Silva, Drugs R. D. 4 (2003) 269.

[8] G. Flesch, E. Francotte, F. Hell, P.H. Degen, J. Chromatogr. 581 (1992) 147.

[9] A. Volosov, A. Sintov, M. Bialer, Ther. Drug Monit. 21 (1999) 219.

[10] A. Volosov, S. Xiaodong, E. Perucca, B. Yagen, A. Sintov, M. Bialer, Clin. Pharmacol. Ther. 66 (1999) 547.

[11] A. Volosov, B. Yagen, M. Bialer, Epilepsia 41 (2000) 1107.

[12] S. Pichini, I. Altieri, A.R. Passa, P. Zuccaro, R. Pacifici, J. Liq. Chromatogr. 18 (1995) 1533.
[13] A. Volosov, M. Bialer, S. Xiaodong, E. Perucca, A. Sintov, B. Yagen, J. Chromatogr. B 738 (2000) 419.

[14] D. Hainzl, A. Parada, P. Soares-da-Silva, Epilepsy Res. 44 (2001) 197.

[15] V.P. Shah, K.K. Midha, J.W.A. Findlay, H.M. Hill, J.D. Hulse, I.J. McGilveray, G. Mckay, K.J. Miller, R.N. Patnaik, M.L. Powell, A. Tonelli, C.T. Viswanathan, A. Yacobi, Pharm. Res. 17 (2000) 1551.

[16] F.T. Peters, H.H. Maurer, Accred. Qual. Assur. 7 (2002) 441.

[17] A.M. Almeida, M.M. Castel-Branco, A.C. Falcão, J. Chromatogr. B 774 (2002) 215 .

[18] S.M. Han, Biomed. Chromatogr. 11 (1997) 259.

[19] R. Mandrioli, N. Ghedini, F. Albani, E. Kenndler, M.A. Raggi, J. Chromatogr. B 783 (2003) 253.

[20] X. Wang, C.B. Ching, Chirality 14 (2002) 798. 